\title{
Candidacidal mechanisms of peritoneal macrophages activated with lymphokines or $\gamma$-interferon
}

\author{
E. BRUMMER and D.A.STEVENS
}

\begin{abstract}
Division of Infectious Diseases, Department of Medicine, Santa Clara Valley Medical Center and Institute for Medical Research, San Jose, CA 95128 and Stanford University, Stanford, CA 94305, USA
\end{abstract}

\begin{abstract}
Summary. The mechanisms by which resident peritoneal macrophages, activated in vitro by lymphokines (LK) or recombinant $\gamma$-interferon (IFN), kill Candida parapsilosis or $C$. albicans were studied. Resident non-activated peritoneal macrophages killed $C$. parapsilosis $(55 \cdot 5 \% \mathrm{SD} 6.8 \%)$, but not $C$. albicans. This killing was completely inhibited by superoxide dismutase (SOD), partially by dimethyl sulphoxide (DMSO), but not by catalase or azide. Killing correlated with a brisk lucigenin-dependent chemiluminescence $(\mathrm{CL})$ response by macrophages interacting with $C$. parapsilosis. No enhanced luminol-dependent $C L$ response was observed in this system. This suggests that $C$. parapsilosis is killed by resident macrophages via a mechanism dependent on the presence of superoxide anion. By contrast, killing of $C$. parapsilosis by activated macrophages $(49.0 \% \mathrm{SD} 5.9 \%)$ was not inhibited by SOD or DMSO, suggesting the induction of a non-oxidative candidacidal mechanism. C. albicans was killed only by macrophages activated with IFN $(52 \cdot 0 \% \mathrm{SD} 3 \cdot 7 \%)$ or LK $(55 \cdot 7 \% \mathrm{SD} 2 \cdot 8 \%)$. Inhibition of killing by SOD was greater in IFN- than in LK-activated macrophages. Conversely, killing by LK-, but not IFN-, activated macrophages was significantly inhibited by catalase, DMSO or azide. The killing by LK-activated macrophages, and its inhibition by scavengers, correlated with the luminol-dependent $\mathrm{CL}$ response. The non-killing resident macrophages interacting with $C$. albicans made lucigenin-dependent $C L$ responses similar to those of activated macrophages. The mechanisms enabling killing of $C$. albicans induced by activation appear to be different for LK and IFN, and appear to depend upon the myeloperoxidase systems and superoxide respectively.
\end{abstract}

\section{Introduction}

Unlike normal polymorphonuclear neutrophils (PMN) and monocytes which kill Candida albicans (Leijh et al., 1977), alveolar (Biggar and Sturgess, 1976) and peritoneal (Peterson et al., 1985) macrophages are deficient in myeloperoxidase (MPO) and lack significant ability to kill C. albicans (Lehrer et al., 1980; Peterson et al., 1985). Furthermore, $C$. albicans resists killing by PMN and monocytes that are genetically deficient in myeloperoxidase (Lehrer and Cline, 1969). Nevertheless, such MPO-deficient leucocytes readily kill other Candida species, e.g., C. parapsilosis, C. krusei, and C. pseudotropicalis, and bacteria (Lehrer, 1972). Although the MPOindependent mechanism is slower, it is efficient (Lehrer, 1972; Lehrer et al., 1975).

Peritoneal macrophages from mice infected with

Received 12 April 1988; revised version accepted 5 Aug. 1988. bacillus Calmette-Guerin (BCG) (Sasada and Johnston, 1980) or resident peritoneal macrophages treated with lymphokines in vitro (Kagaya and Fukazawa, 1981) have been reported to kill $C$. albicans. Recently we have reported that recombinant $\gamma$-interferon (IFN) activates resident peritoneal macrophages in vitro for significant killing $(44 \%)$ of $C$. albicans (Brummer et al., 1985). Although killing of $C$. albicans by activated macrophages is likely to be important in host defence against $C$. albicans, the mechanisms by which activated macrophages kill $C$. albicans is unclear.

The purpose of the present study was to elucidate candidacidal mechanisms of resident and activated peritoneal macrophages by use of new reagents and techniques. With the use of lucigenin, that reacts primarily with superoxide anion (Minkenberg and Ferber, 1984; Muller-Peddinghaus, 1984) and luminol, oxygen radicals generated by interaction of activated or resident macrophages with viable 
candida were measured by chemiluminescence. Concomitantly, the ability of oxygen radical scavengers, or enzyme inhibitors, to decrease the killing of candida by macrophages was assessed.

\section{Materials and methods}

\section{Animals}

Male BALB/cByJIMR mice, 8-12 weeks of age, were obtained from the breeding colony of the Institute for Medical Research, San Jose, CA, for use in these experiments.

\section{Reagents and media}

Tissue-culture medium RPMI-1640 with L-glutamine, Eagle's Minimum Essential Medium (MEM), heatinactivated fetal bovine serum (FBS), and penicillinstreptomycin, $10000 \mathrm{U} / \mathrm{ml}-10000 \mu \mathrm{g} / \mathrm{ml}$, respectively, $(\mathrm{P} / \mathrm{S})(\mathrm{Gibco}, \mathrm{Grand}$ Island, NY) were used and complete tissue culture medium (CTCM) comprised $89 \mathrm{ml}$ of RPMI-1640, $10 \mathrm{ml}$ of FBS, and $1 \mathrm{ml}$ of P/S. Concanavolin A (Con A) and $\alpha$-methyl-D-mannoside, grade III (aMM) (Sigma Chemical Co., St Louis, MO), preservative-free heparin (American Scientific Products, Sunnyvale, CA), 96-well half-area (A/2) tissue-culture plates (Costar Co., Cambridge, MA) and murine $\gamma$-interferon produced by recombinant DNA technology, and hyperimmune rabbit antibody $(0.155 \mathrm{mg} / \mathrm{ml})$ to murine $\gamma$-IFN (Genentech Corp., South San Francisco, CA) as described by Celada et al. (1984) and Svedersky et al. (1984) were employed. Luminol (5-amino-2,3-dihydro-1, 4-phthaliazinedione) and lucigenin (bis- $N$-methylairidinium nitrate) (Sigma) were dissolved in dimethyl sulphoxide (DMSO; Eastman Kodak Co., Rochester, NY) to form stock solutions of $10 \mathrm{mg} / \mathrm{ml}$. Superoxide dimutase (SOD; $3000 \mathrm{U} / \mathrm{mg}$ of protein) and catalase $(25000 \mathrm{U} / \mathrm{mg}$ of protein) (Sigma) were dialysed against phosphate-buffered saline (PBS) before use. Stock 0.1 M sodium azide (Fisher Scientific Co., Fair Lawn, NJ) was prepared in saline. Horseradish peroxidase (HPO; Sigma) was dialysed and used as previously described (Sugar et al., 1983).

\section{Fungi}

C. parapsilosis and C. albicans ATCC 56882 were grown in yeast nitrogen broth (Difco) at $35^{\circ} \mathrm{C}$ for 3-4 days. Blastomyces dermatitidis ATCC 26199, an isolate shown to be virulent in mice, was grown and used as previously described (Brummer et al., 1985; Brummer and Stevens, 1984). Fungi were washed twice in $4 \mathrm{ml}$ of saline, pelleted cells were suspended in CTCM, and units (single or multicellular) counted with a haemacytometer. Viable cfu were determined by plating $1 \mathrm{ml}$ of appropriate dilutions in quadruplicate on blood-agar plates. Killed $C$. albicans was prepared by heating for $1 \mathrm{~h}$ at $60^{\circ} \mathrm{C}$.

\section{Peritoneal macrophages}

Peritoneal cells $(\mathrm{PC})$ were collected from the abdominal cavity of each mouse by repeated lavage with a total of $10 \mathrm{ml}$ of MEM containing heparin $10 \mathrm{U} / \mathrm{ml}$. PC from mice were pelleted by centrifugation $(200 \mathrm{~g}, 10 \mathrm{~min})$ and pooled. The number of cells $/ \mathrm{ml}$ was determined with a haemacytometer. PC were dispensed $(0.1 \mathrm{ml}$ of $5 \times$ $10^{6} \mathrm{PC} / \mathrm{ml}$ of CTCM) into the wells of an $\mathrm{A} / 2 \mathrm{Costar}$ plate and the plate was incubated at $37^{\circ} \mathrm{C}$ in $\mathrm{CO}_{2} 5 \%$ in air for $2 \mathrm{~h}$, then the non-adherent cells were removed by aspiration and each well was washed once with CTCM. When the number of non-adherent cells was subtracted from the number of incubated PC, the average number of adherent $\mathrm{PC} /$ well was $2.5 \times 10^{5}$. Adherent cells were previously shown to be $90 \%$ positive for non-specific esterase (Brummer et al., 1983).

\section{Treatment and challenge of macrophages}

Macrophage monolayers were incubated overnight $\left(37^{\circ} \mathrm{C}, \mathrm{CO}_{2} 5 \%\right.$ in air) with $0.1 \mathrm{ml}$ of CTCM or CTCM containing IFN $200 \mathrm{U} / \mathrm{ml}$ or Con A-stimulated spleencell culture supernates (obtained as described in the next paragraph) containing $50 \mathrm{mM}$ aMM. After incubation, culture supernates were aspirated and monolayers were challenged with $0.1 \mathrm{ml}$ of $C$. albicans or $C$. parapsilosis suspensions (10000 fungal units/ml of CTCM) plus $0.01 \mathrm{ml}$ of fresh mouse serum with or without SOD, catalase, DMSO, or sodium azide. Co-cultures were incubated at $37^{\circ} \mathrm{C}$ in $\mathrm{CO}_{2} 5 \%$ in air for $2 \mathrm{~h}$. Cultures were harvested by aspiration and repeated washing of culture wells with distilled water to a final volume of $10 \mathrm{ml}$. Microscopic examination of washed wells indicated that there was complete removal of macrophages. To determine the number of cfu/culture, $1 \mathrm{ml}$ of the $10 \mathrm{ml}$ of distilled water from the wells was plated on a blood-agar plate and colonies were counted after incubation for 2 days at $35^{\circ} \mathrm{C}$.

\section{Spleen-cell supernates}

Spleen cells were obtained from normal mice and cultured as previously described (Brummer and Stevens, 1984). Supernates were generated by incubation of $10^{7}$ spleen cell $/ \mathrm{ml}$ of CTCM with or without Con A $5 \mu \mathrm{g} / \mathrm{ml}$ in 20-well tissue-culture plates (Falcon, Oxnard, CA), $2 \mathrm{ml} /$ well at $37^{\circ} \mathrm{C}$ in $\mathrm{CO}_{2} 5 \%$ in air for 1 day. Supernates were harvested from pooled cultures by centrifugation $(400 \mathrm{~g}, 10 \mathrm{~min})$ and filtration through $0.45-\mu \mathrm{m}$ filters (Millipore Corp., Bedford, MA). Portions of supernates were stored at $-70^{\circ} \mathrm{C}$ until used.

\section{Chemiluminescence}

To detect the products of oxidative metabolism subsequent to challenge of macrophages with fungal units in fresh serum, the luminol method of Allen and Loose (1976) and the lucigenin method of Minkenberg and Ferber (1984) were used. Briefly, $0.5 \mathrm{ml}$ of PC $\left(5 \times 10^{6}\right.$ 
$\mathrm{PC} / \mathrm{ml}$ of CTCM) were dispensed into each glass microsample vial $(15 \times 45 \mathrm{~mm})$ and incubated at $37^{\circ} \mathrm{C}$ for $2 \mathrm{~h}$ in $\mathrm{CO}_{2} 5 \%$ in air. Non-adherent cells were removed by aspiration and the monolayers were washed once with CTCM. Monolayers were treated overnight with $0.5 \mathrm{ml}$ of CTCM, Con A supernates containing $50 \mathrm{mM} \mathrm{aMM}$, or IFN (200 U/ml CTCM). After treatment and removal of the supernates, monolayers were challenged with $0 \cdot 1 \mathrm{ml}$ of luminol or lucigenin ( 1 in 250 or 1 in 100 dilutions of stock $10 \mathrm{mg} / \mathrm{ml}$ in DMSO, respectively), $0.05 \mathrm{ml}$ of fresh mouse serum, $0.15 \mathrm{ml}$ of PBS, and $0.1 \mathrm{ml}$ of fungal suspension $\left(10 \times 10^{6}\right.$ cells $/ \mathrm{ml}$ of PBS $)$ and assayed at room temperature. When catalase or SOD was added to the mixtures, corresponding volumes of PBS were omitted. Photon emission was measured in a scintillation counter (Mark II, Nuclear Chicago) at room temperature with the windows set on "manual" and levels at L-infinity. The manual setting permitted rapid counting of samples, and the $\mathrm{cpm}$ was calculated from the counting time ( $\leq$ $0.2 \mathrm{~min}$ ) registered by the scintillation counter. Chemiluminescence values in the absence of fungi were less than the time 0 values in the presence of fungi shown in the figures, in all cases.

\section{Phagocytosis}

PC $\left(5 \times 10^{6} / \mathrm{ml}\right.$ of CTCM $)$ were dispensed, $0.25 \mathrm{ml} /$ chamber of Lab-Tek tissue-culture slides (Miles Scientific, Naperville, IL). After incubation for $2 \mathrm{~h}$ at $37^{\circ} \mathrm{C}$, non-adherent cells were removed by aspiration and the monolayers were washed once with CTCM. Monolayers were treated overnight with $0.25 \mathrm{ml}$ of CTCM, IFN $(200 \mathrm{U} / \mathrm{ml}$ of CTCM) or Con A supernates containing $50 \mathrm{mM}$ a MM at $37^{\circ} \mathrm{C}$ in $\mathrm{CO}_{2} 5 \%$ in air. After treatment, supernates were aspirated and monolayers challenged with $0.2 \mathrm{ml}$ of $C$. albicans $\left(5 \times 10^{6}\right.$ cells $/ \mathrm{ml}$ of CTCM) plus $10 \%$ fresh mouse serum. Challenged monolayers were incubated for $2 \mathrm{~h}$ at $37^{\circ} \mathrm{C}$ in $\mathrm{CO}_{2} 5 \%$ in air. After incubation, challenged monolayers were washed three times with saline, then dried, fixed, and stained with Diff-Quik (American Scientific Products, McGraw Park, IL).

\section{Statistics}

The statistical significance of the differences between the means was determined by Student's $t$ test.

\section{Results}

Susceptibility of C. parapsilosis and C. albicans to the $\mathrm{H}_{2} \mathrm{O}_{2}$ - $\mathrm{HPO}$-halide system

The sensitivity of $C$. parapsilosis and $C$. albicans to the toxic products of a cell-free $\mathrm{H}_{2} \mathrm{O}_{2}$-HPOhalide system was tested as previously described (Sugar et al., 1983) with $B$. dermatitidis being used in comparison. All fungi were sensitive to $5 \times 10^{-6} \mathrm{M}$
Table I. Killing of $C$. albicans, $C$. parapsilosis and $B$. dermatitidis in the $\mathrm{H}_{2} \mathrm{O}_{2}$-HPO-halide system*

\begin{tabular}{l|cccc}
\hline & \multicolumn{4}{|c}{ Percentage killing at $\mathrm{H}_{2} \mathrm{O}_{2}$ concentration } \\
& \multicolumn{4}{|c}{} \\
\cline { 2 - 5 } Fungus species & $5 \times 10^{-5}$ & $5 \times 10^{-6}$ & $5 \times 10^{-7}$ & $5 \times 10^{-8}$ \\
\hline C. parapsilosis & 100 & 100 & 2 & 0 \\
C. albicans & 100 & 100 & 23 & 0 \\
B. dermatitidis & 100 & 100 & 0 & 0 \\
\end{tabular}

${ }^{*} \mathrm{KI}, 5 \times 10^{-4} \mathrm{M} ; \mathrm{HPO}$ as peroxidase $14 \mathrm{U} / \mathrm{ml}$.

$\mathrm{H}_{2} \mathrm{O}_{2}$ interacting with $\mathrm{HPO} 14 \mathrm{U} / \mathrm{ml}$ and $\mathrm{KI} 5 \times$ $10^{-4} \mathrm{M}$ (table I). In a second experiment similar killing results were obtained. Individually the components $-5 \times 10^{-4} \mathrm{M} \mathrm{H}_{2} \mathrm{O}_{2}, 5 \times 10^{-4} \mathrm{M} \mathrm{KI}$ or HPO $14 \mathrm{U} / \mathrm{ml}$ - were not toxic. Killing was completely inhibited by catalase $200 \mathrm{U} / \mathrm{ml}$, but not by SOD $450 \mathrm{U} / \mathrm{ml}$. These results indicate that the resistance of $C$. albicans to killing by resident macrophages in comparison with $C$. parapsilosis, is not due to resistance to the products of the $\mathrm{H}_{2} \mathrm{O}_{2}$ HPO-halide system.

\section{Phagocytosis}

Differences in phagocytosis of $C$. albicans by macrophage monolayers treated overnight with CTCM, IFN, or Con A supernates were assessed by the slide Lab-Tek tissue-culture chamber method. Macrophages in CTCM ingested $C$. albicans as readily as those treated with IFN or Con A supernates and the inability of resident macrophages to kill C.albicans is not explained by lack of phagocytic ingestion.

Effect of oxygen-radical scavengers on killing of $C$. parapsilosis by macrophages

The killing of $C$. parapsilosis in $2 \mathrm{~h}$ by resident macrophages $(55.5 \% \mathrm{SD} 6.8 \%)$ was extremely sensitive to inhibition $(100 \%)$ by SOD $450 \mathrm{U} / \mathrm{ml}$ and, to a lesser extent, by DMSO (33\% inhibition) (table II). Killing was not inhibited by heated SOD $450 \mathrm{U} /$ $\mathrm{ml}$, catalase $20000 \mathrm{U} / \mathrm{ml}$ or $1 \mathrm{~mm}$ sodium azide. Killing increased with incubation time, e.g., at $3 \mathrm{~h}$ it increased to $75.0 \% \mathrm{SD} 2.8 \%(\mathrm{n}=2)$. These findings indicate that resident macrophages killed $C$. parapsilosis, not by a $\mathrm{H}_{2} \mathrm{O}_{2}-\mathrm{MPO}$-halide system, but by a mechanism requiring superoxide anion, and to some extent the generation of hydroxyl radicals.

Resident macrophages treated with Con A supernates or IFN did not exhibit enhanced killing 
$(49.0 \% \mathrm{SD} 5.9 \%$ and $57.6 \mathrm{SD} 7 \cdot 2 \%)$ compared to resident macrophages $(55 \cdot 5 \% \mathrm{SD} 6 \cdot 8 \%$ ) (table II). The primary effect of these treatments of macrophages was resistance to inhibition of killing by SOD $450 \mathrm{U} / \mathrm{ml}$ or $300 \mathrm{~mm}$ DMSO (table II). Azide (1 $\mathrm{mM}$ ) did not significantly inhibit killing of $C$. parapsilosis by macrophages treated with Con $\mathrm{A}$ supernate $(66 \%$ vs $52 \%$ in the presence of azide) or by IFN $200 \mathrm{U} / \mathrm{ml}(77 \%$ vs. $69 \%$ in the presence of azide). Since killing was not inhibited by catalase, or significantly by azide, the mechanism by which treated macrophages killed $C$. parapsilosis was relatively independent of a need for generating oxygen radicals.

\section{Effect of oxygen-radical scavengers on killing of $C$. albicans by activated macrophages}

Although resident peritoneal macrophages killed C. parapsilosis efficiently, they were not able to kill C. albicans. However, as previously reported, macrophages treated overnight with $\gamma$-IFN or supernates from Con A-stimulated spleen-cell cultures killed C. albicans (Brummer et al., 1985). We confirmed those results in the present study (table III). Killing of $C$. albicans by IFN treated macrophages was inhibited $76 \%$ by SOD $450 \mathrm{U} / \mathrm{ml}$ but not by catalase or DMSO (table III). Moreover, $1 \mathrm{~mm}$ azide did not significantly inhibit killing $(50 \%$ vs. $47 \%$ in the presence of azide).

By contrast, killing by macrophages activated with Con A supernates was inhibited significantly by catalase, DMSO, and SOD $4500 \mathrm{U} / \mathrm{ml}$ (table III). These agents resulted in an inhibition of killing by $24 \%, 42 \%$, and $46 \%$, respectively. Furthermore, $1 \mathrm{mM}$ azide significantly inhibited killing (54\% vs. $13 \%$ in the presence of azide; $77 \%$ inhibition). These results clearly implicate involvement of the $\mathrm{H}_{2} \mathrm{O}_{2}$-MPO-halide system in the killing of $C$. albicans by macrophages activated with Con $\mathrm{A}$ supernates. These findings show that IFN-activated macrophages killed $C$. albicans as efficiently as Con

Table II. Effect of oxygen-radical scavengers on the killing of $C$. parapsilosis by resident and activated peritoneal macrophages

\begin{tabular}{|c|c|c|c|c|c|}
\hline \multirow{3}{*}{$\begin{array}{l}\text { Macrophage* } \\
\text { treatment }\end{array}$} & \multicolumn{5}{|c|}{ Percentage (mean $\pm \mathrm{SD}$ ) reduction of inoculum cfu in $2 \mathrm{~h}$ (number of experiments) } \\
\hline & \multirow[b]{2}{*}{ CTCM } & \multicolumn{2}{|c|}{$\operatorname{SOD}(\mathrm{U} / \mathrm{ml})$} & \multirow{2}{*}{$\begin{array}{c}\text { Catalase } \\
(20000 \mathrm{U} / \mathrm{ml})\end{array}$} & \multirow{2}{*}{$\begin{array}{c}\text { DMSO } \\
(300 \mathrm{mM})\end{array}$} \\
\hline & & 4500 & 450 & & \\
\hline $\begin{array}{l}\text { CTCM } \\
\text { Con A sup } \\
\gamma \text {-IFN }\end{array}$ & $\begin{array}{l}55 \cdot 5 \pm 6 \cdot 8(6) \\
49 \cdot 0 \pm 5 \cdot 9(4) \\
57 \cdot 6 \pm 7 \cdot 2(3)\end{array}$ & $\begin{array}{c}\text { ND } \\
43 \cdot 3 \pm 16 \cdot 1(3) \\
+31 \cdot 6 \pm 11 \cdot 0(3)\end{array}$ & $\begin{array}{l}+0 \cdot 0 \pm 0 \cdot 0(3) \\
48 \cdot 2 \pm 8 \cdot 0(4) \\
56 \cdot 3 \pm 5 \cdot 7(3)\end{array}$ & $\begin{array}{l}65 \cdot 0 \pm 5 \cdot 6(2) \\
67 \cdot 0 \pm 2 \cdot 8(2) \\
69 \cdot 0 \pm 2 \cdot 8(2)\end{array}$ & $\begin{array}{r}+37 \cdot 3 \pm 4 \cdot 9(3) \\
64 \cdot 5 \pm 9 \cdot 1(2) \\
53 \cdot 5 \pm 4 \cdot 9(2)\end{array}$ \\
\hline
\end{tabular}

*Resident peritoneal macrophages incubated overnight with complete tissue culture medium (CTCM), Con A-stimulated spleen cell culture supernates (Con A sup) or recombinant $\gamma$-IFN $200 \mathrm{U} / \mathrm{ml}$.

$\dagger$ Significantly different $(\mathrm{p}<0 \cdot 05)$ from CTCM control.

$\mathrm{ND}=$ not done.

Table III. Effect of oxygen-radical scavengers on the killing of C. albicans by lymphokine or $\gamma$-IFN-activated macrophages

\begin{tabular}{|c|c|c|c|c|c|}
\hline \multirow{3}{*}{$\begin{array}{l}\text { Macrophage* } \\
\text { Treatment }\end{array}$} & \multicolumn{5}{|c|}{ Percentage (mean $\pm \mathrm{SD}$ ) reduction of inoculum cfu in $2 \mathrm{~h}$ (number of experiments) } \\
\hline & \multirow[b]{2}{*}{ СТСМ } & \multicolumn{2}{|c|}{$\operatorname{SOD}(\mathrm{U} / \mathrm{ml})$} & \multirow{2}{*}{$\begin{array}{c}\text { Catalase } \\
(20000 \mathrm{U} / \mathrm{ml})\end{array}$} & \multirow{2}{*}{$\begin{array}{c}\text { DMSO } \\
(300 \mathrm{mM})\end{array}$} \\
\hline & & 4000 & 450 & & \\
\hline $\begin{array}{l}\gamma \text {-IFN } \\
\text { Con A sup }\end{array}$ & $\begin{array}{l}52 \cdot 0 \pm 3 \cdot 7(5) \\
55 \cdot 7 \pm 2 \cdot 8(4)\end{array}$ & $\begin{array}{r}\dagger 2 \cdot 3 \pm 2 \cdot 5(3) \\
\dagger 30 \cdot 0 \pm 13 \cdot 7(3)\end{array}$ & $\begin{array}{r}+12 \cdot 3 \pm 8 \cdot 0(3) \\
45 \cdot 3 \pm 9 \cdot 0(3)\end{array}$ & $\begin{array}{r}65 \cdot 6 \pm 4 \cdot 6(3) \\
+42 \cdot 5 \pm 5 \cdot 8(4)\end{array}$ & $\begin{array}{r}46 \cdot 3 \pm 4 \cdot 9(3) \\
+32 \cdot 2 \pm 9 \cdot 2(4)\end{array}$ \\
\hline
\end{tabular}

*Resident peritoneal macrophages incubated overnight with complete tissue culture medium (CTCM; see table II); Con Astimulated spleen cell culture supernates (Con A sup); or recombinant $\gamma$-IFN $200 \mathrm{U} / \mathrm{ml}$.

†Significantly different $(\mathrm{p}<0 \cdot 05)$ from CTCM control. 


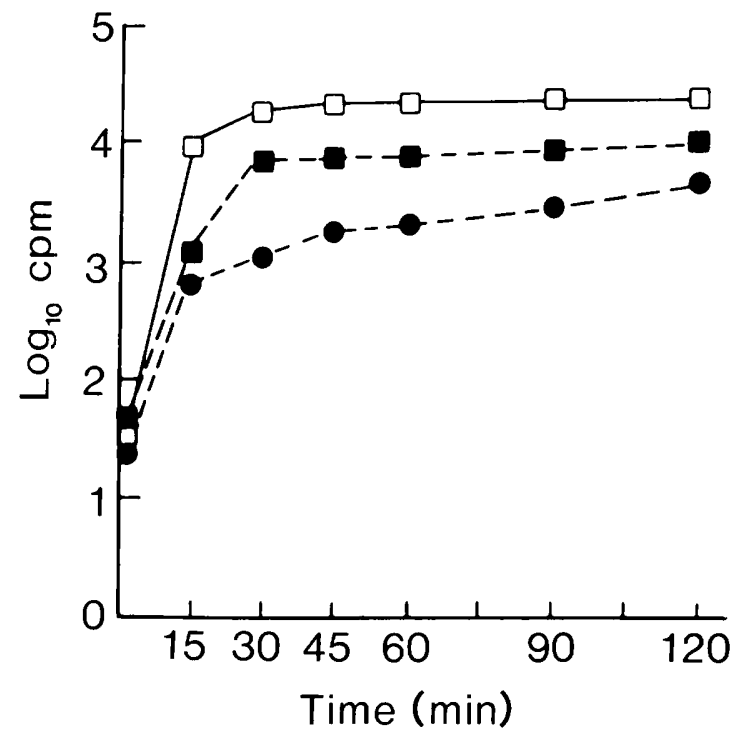

Fig. 1. Generation of lucigenin-enhanced CL by the interaction of macrophages and $C$. parapsilosis. The $\mathrm{CL}$ produced by interaction of macrophages, treated with CTCM ( $\square$ ), Con A supernates $(\square)$ or IFN $200 \mathrm{U} / \mathrm{ml}(\mathbf{O})$, and C. parapsilosis are plotted against time.

A supernate-activated macrophages but by a novel and different mechanism, e.g., one that required only the generation of superoxide anion.

\section{Lucigenin-enhanced chemiluminescence responses generated by interaction of macrophages and $C$. parapsilosis}

The greatest superoxide anion-dependent lucigenin $\mathrm{CL}$ responses were made by the interaction of resident macrophages and $C$. parapsilosis (fig. 1). The response reached near maximum by $30 \mathrm{~min}$ and was maintained for at least $120 \mathrm{~min}$. Interaction of Con A supernate- or IFN-activated macrophages with $C$. parapsilosis produced a similar CL profile but with one half $\log _{10}$ and one $\log _{10}$ fewer cpm, respectively (fig. 1). Similar results were obtained in a second experiment in which the resident macrophages gave a greater lucigenin $C L$ response to $C$. parapsilosis $\left(10^{3.95} \mathrm{cpm}\right)$ than did activated (Con A supernate) macrophages $\left(10^{3.57} \mathrm{cpm}\right)$. Since resident and activated macrophages killed $C$. parapsilosis to the same extent, the magnitude of lucigenin $C L$ responses and superoxide anion production per se did not parallel killing. However, the brisk lucigenin CL response made by resident macrophages interacting with $C$. parapsilosis was probably related to crucial candidacidal mechanisms, as evidenced by inhibition of that mechanism with SOD.

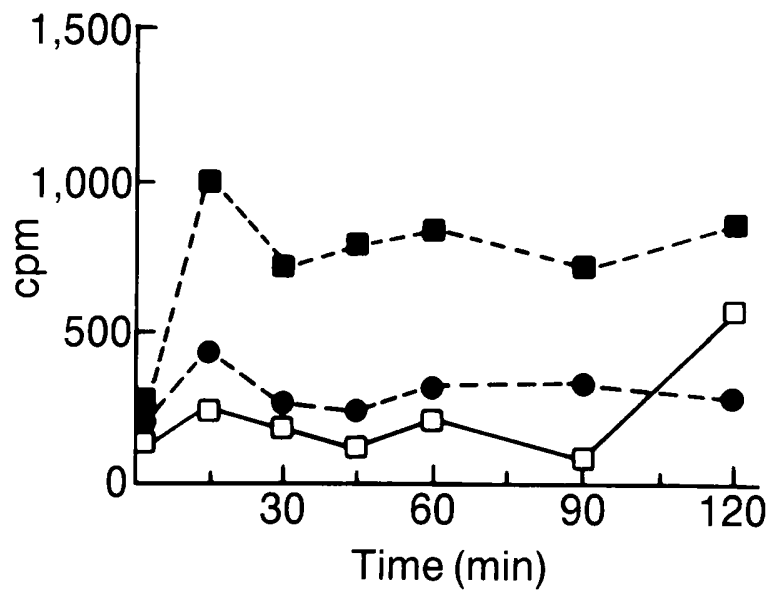

Fig. 2. Generation of luminol-enhanced $C L$ by the interaction of macrophages and $C$. parapsilosis. The CL produced by the interaction of macrophages treated with CTCM ( $\square$ ), IFN $200 \mathrm{U} / \mathrm{ml}(\mathbf{)})$ or Con A supernates $(\square)$ and $C$. parapsilosis is given with time.

Luminol-enhanced chemiluminescence responses generated by interaction of macrophages and $C$. parapsilosis

Resident macrophages plus C. parapsilosis gave a peak luminol-enhanced CL response $143 \%$ that of macrophages that had not interacted with $C$. parapsilosis. However, Con A supernate-treated macrophages exhibited an early five-fold greater CL response to $C$. parapsilosis than resident macrophages (fig. 2), and this was sustained for at least $120 \mathrm{~min}$. IFN-treated macrophages plus $C$. parapsilosis produced a two-fold greater $\mathrm{CL}$ response than resident macrophages after incubation for $15 \mathrm{~min}$. These results suggest that activated macrophages interacting with $C$. parapsilosis generated oxygen radicals detectable by luminol-enhanced CL. However, the levels of these products did not play a critical role in the mechanisms of killing because killing was not inhibited by catalase or DMSO, and because activated macrophages did not kill $C$. parapsilosis better than resident macrophages.

\section{Lucigenin-enhanced chemiluminescence generated by} interaction of macrophages and C. albicans

When resident or activated macrophages were challenged with viable $C$. albicans, similar levels of lucigenin-enhanced CL were recorded (fig. 3). Killed $C$. albicans cells were more effective stimulators than viable cells and elicited a 10 -fold greater CL response (fig. 3). In other experiments, killed $C$. albicans elicited greater peak CL responses in 


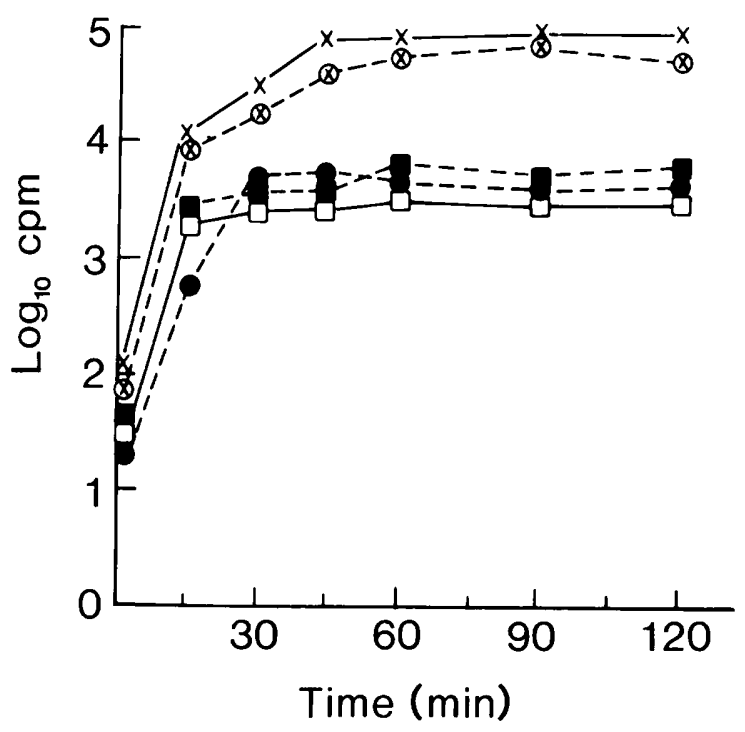

Fig. 3. Lucigenin-enhanced $\mathrm{CL}$ generated by interaction of macrophages and $C$. albicans. The $C L$ produced by interaction of macrophages treated with CTCM $(\square)$, Con A supernates ( $\square$ ) or IFN $200 \mathrm{U} / \mathrm{ml}()_{)}$and viable $C$. albicans is given with that of macrophages treated with CTCM $(\mathrm{x}-\mathrm{x})$ or Con A supernates $(\otimes-\otimes)$ interacting with killed C. albicans.

resident macrophages than viable cells did, e.g., $10^{5 \cdot 24} \mathrm{cpm}$ vs. $10^{4 \cdot 28} \mathrm{cpm}$, and viable cells stimulated resident and Con $A$ supernate-activated macrophages to a similar extent, e.g., $10^{3 \cdot 79} \mathrm{cpm}$ vs. $10^{3 \cdot 86} \mathrm{cpm}$, respectively. Since only activated macrophages killed $C$. albicans, generation of a lucigenin-enhanced CL response by macrophages did not correlate with their capacity to kill $C$. albicans. Lucigenin-enhanced $\mathrm{CL}$ responses were superoxide anion-dependent because the response was completely inhibited by SOD $450 \mathrm{U} / \mathrm{ml}$, but not by catalase $20000 \mathrm{U} / \mathrm{ml}$ (data not shown).

\section{Luminol-enhanced $C L$ generated by interaction of $C$. albicans with macrophages}

Macrophages activated by treatment with supernates from Con A-stimulated spleen cells generated a luminol-enhanced $\mathrm{CL}$ response with viable or killed $C$. albicans (fig. 4). These CL responses were 13-15-fold greater than that of resident macrophages with $C$. albicans (fig. 4). In a second experiment, CL responses were $8 \cdot 75$-fold greater with Con A supernate-activated macrophages interacting with $C$. albicans than with resident macrophages and $C$. albicans. The enhanced CL responses paralleled the ability of Con A supernatetreated macrophages to kill $C$. albicans. The CL response was inhibited by $1 \mathrm{~mm}$ azide and catalase

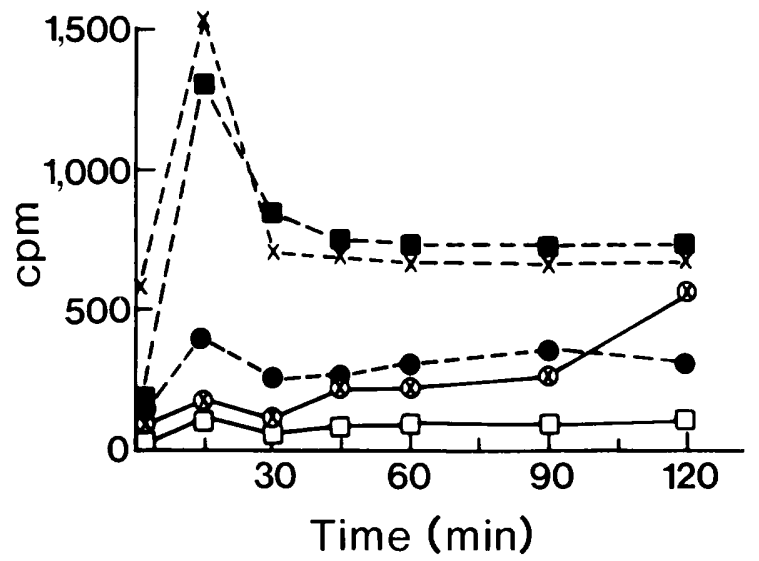

Fig. 4. Luminol-enhanced $C L$ generated by the interaction of macrophages with $C$. albicans. The $C L$ produced by the interaction of macrophages treated with CTCM ( $\square$ ), Con A supernates $(\square)$ or IFN $200 \mathrm{U} / \mathrm{ml}(\bigcirc)$ and viable $C$. albicans is given with the responses of macrophages treated with CTCM $(\otimes-\otimes)$ and Con A supernates $(\mathrm{x}-\mathrm{x})$ interacting with killed $C$. albicans.

$20000 \mathrm{U} / \mathrm{ml}$, indicating its dependence on the $\mathrm{H}_{2} \mathrm{O}_{2}$-MPO-halide system (data not shown). These results also correlated with significant inhibition of killing by $1 \mathrm{mM}$ azide, catalase $20000 \mathrm{U} / \mathrm{ml}$ and $300 \mathrm{~mm}$ DMSO (table III).

Macrophages treated with IFN, when interacting with $C$. albicans, also produced a luminol-enhanced CL response but at a three-fold lower level (fig. 4). Similar results were obtained in a second experiment. This low CL response correlated with failure of catalase, azide, or DMSO to inhibit killing of $C$. albicans by IFN-activated macrophages, and provided additional evidence for a killing mechanism for $C$. albicans independent of the $\mathrm{H}_{2} \mathrm{O}_{2}$-MPOhalide system.

\section{Discussion}

In this study we have shown that resident macrophages can kill $C$. parapsilosis, and that this killing activity is susceptible to SOD and DMSO and resistant to catalase and azide. Macrophages treated with Con A supernates or IFN did not show increased killing of $C$. parapsilosis. The killing by Con A supernate-treated macrophages was resistant to SOD, catalase, DMSO, and azide, whereas killing by macrophages treated with IFN was partially resistant to SOD and resistant to the other three inhibitors. Chemiluminescence after contact with this fungus, assayed with lucigenin, showed that resident macrophages had greater activity than treated macrophages, even though killing was the 
same. Resident macrophages did not demonstrate chemiluminescence with luminol; treated macrophages had enhanced chemiluminescence with this method, but killing was the same.

In contrast, only treated macrophages became activated to kill $C$. albicans. The killing induced by Con A supernates was susceptible to azide, catalase, DMSO, and SOD. The killing induced by IFN was susceptible to SOD but resistant to the other inhibitors. Chemiluminescence after contact with C. albicans assayed with lucigenin was similar in resident and activated macrophages, though only activated macrophages killed the fungus. Macrophage chemiluminescence assayed with luminol was enhanced by Con A supernates; this enhancement was neutralised by the four inhibitors, which correlated with their inhibition of killing of $C$. albicans by these cells. Luminol-assayed chemiluminescence after IFN treatment showed a smaller increase; the resistance of this enhancement to inhibitors correlated with their lack of effect on killing of C. albicans by IFN-treated cells.

We confirmed that $C$. albicans is sensitive to products of the $\mathrm{H}_{2} \mathrm{O}_{2}$-HPO-halide system first reported by Klebanoff (1968), and showed that resistance of $C$. albicans to killing by macrophages, compared to $C$. parapsilosis, is not due to greater resistance to these toxic products. Although Lehrer (1972) and Sasada and Johnston (1980) have reported that $C$. parapsilosis is more resistant to killing by $\mathrm{H}_{2} \mathrm{O}_{2}$ than $C$. albicans, the concentrations required for killing candida $\left(10^{-3}\right.$ and $\left.10^{-2} \mathrm{M}\right)$ are not physiologically realistic. On the other hand, resistance of $C$. albicans to killing in a MPOdeficient system has been linked to marked insensitivity of $C$. albicans to killing by lysosomal cationic proteins $(50 \mu \mathrm{g} / \mathrm{ml})$ compared to $C$. parapsilosis (Lehrer et al., 1975).

Phagocytosis of $C$. albicans by non-activated macrophages did not differ from that by activated macrophages. These observations agree with those of Sasada and Johnston (1980), who did not find a correlation between the degree of phagocytosis and ability to kill C. albicans or C. parapsilosis. Resident macrophages phagocytose candida as efficiently as activated macrophages, i.e., $>90 \%$ of macrophages ingest candida.

The data presented agree with earlier reports by Lehrer (1972) that $C$. parapsilosis can be killed by microbicidal mechanisms of macrophages that do not require the MPO system. We confirm that $1-$ $2 \mathrm{~mm}$ sodium azide does not inhibit killing and, in our hands, catalase also does not inhibit killing. Furthermore, we showed that the killing mechanism is superoxide anion-dependent and that killing is mediated partially by generation of hydroxyl radicals. In this respect, our results agree with those of Sasada and Johnston (1980), who reported that killing was inhibited best by SOD and to a lesser extent by benzoate, another hydroxyl radical scavenger.

On the other hand, the mechanism for the killing of C. parapsilosis by in-vitro activated macrophages was different; it was insensitive to inhibition by SOD and DMSO. Thus, the mechanism appears to be independent of any need to generate superoxide anions or hydroxyl radicals. We speculate that this mechanism may involve enhancement of the candidacidal effects of lysosomal cationic proteins described by Patterson-Delafield et al. (1980). Our results with in-vitro activated macrophages differ very much from those reported by Sasada and Johnston (1980) for macrophages elicited by LPS in normal mice or by antigen in BCG-infected mice, e.g., they reported that killing by elicited macrophages was inhibited by SOD to the same extent as killing by resident macrophages. Elicited macrophages may contain recently migrated MPOcontaining monocytes and also resident macrophages that have ingested MPO from PMN (Heifets et al., 1980; Chapes and Haskill, 1983; Peterson et al., 1985); consequently, it is not possible to compare these data with our results with resident macrophages activated in vitro.

Treatment of resident macrophages with IFN enables them to kill $C$. albicans by a mechanism that requires generation of superoxide anion but does not require the $\mathrm{H}_{2} \mathrm{O}_{2}-\mathrm{MPO}$-halide system. The induced killing mechanism does not depend upon enhanced levels of superoxide production, because superoxide anion production by resident and activated macrophages in response to $C$. albicans were similar, as measured by lucigeninenhanced CL. Our results suggest that IFNactivated macrophages are able to kill $C$. albicans by a presently undefined mechanism that uses normally available superoxide anion levels which per se are not toxic. Furthermore, the killing mechanism does not appear to involve the generation of hydroxyl radicals by the Haber-Weiss reaction $\left(\mathrm{O}_{2}^{-}+\mathrm{H}_{2} \mathrm{O}_{2}\right.$ to give $\left.\mathrm{OH} \cdot+\mathrm{OH}^{-}+\mathrm{O}_{2}\right)$ because killing is not inhibited by either catalase or DMSO.

Supernates from Con A-stimulated spleen-cell cultures activate resident macrophages to kill $C$. albicans by mechanisms involving the $\mathrm{H}_{2} \mathrm{O}_{2}$-MPOhalide system, as evidenced by inhibition of killing with azide, catalase, and DMSO. A luminolenhanced CL response to $C$. albicans also indicates the presence of such a system (DeChatelet et al., 
1982; Dahlgren and Stendahl, 1983). These results indicate that these supernates contained factors (lymphokines) that induced enough MPO in the treated macrophages to support these reactions. The supernates contained natural $\gamma$-IFN (Brummer et al., 1985), which is a glycosylated dimer of $28 \mathrm{Kda}$ (Havell and Spitalny, 1984) and is the major activating factor present (Brummer et al., 1985). However, the action of other factors present in supernates, working alone or synergistically with natural $\gamma$-IFN, cannot be ruled out. Apparently recombinant $\gamma$-IFN, which is nonglycosylated $(15 \mathrm{Kda})$, alone does not produce this level of effects. When the concentration of IFN was increased above $200 \mathrm{U} / \mathrm{ml}$, killing was not increased (Brummer et al., 1985) nor were the luminolenhanced CL responses.

Our findings that Con A supernates and recombinant $\gamma$-IFN caused killing of $C$. albicans by different mechanisms in resident peritoneal macrophages are in contrast with those reported by Murray et al. (1983) in the human monocytederived macrophage vs. Leishmania donovani or Toxoplasma gondii systems, e.g. killing of $T$. gondii by macrophages treated for 3 days with Con $A$ supernates or recombinant $\gamma$-IFN was inhibited by SOD, catalase, and mannitol, suggesting that either treatment induced the MPO system (Murray et al., 1985). Further study with our system is needed to determine if a 3 day treatment of resident macrophages with murine $\gamma$-IFN would also induce such levels of MPO. On the other hand, evidence for the induction of a MPO-independent killing mechanism in macrophages from patients with chronic granulomatous disease by IFN was obtained (Murray et al., 1985). Although this mechanism was only $50 \%$ as effective as the MPO-dependent system, it was inducible by recombinant $\gamma$-IFN. More.recently

\section{REFERENCES}

Allen R C, Loose L D 1976 Phagocytic activation of a luminoldependent chemiluminescence in rabbit alveolar and peritoneal macrophages. Biochemical and Biophysical Research Communications 69: 245-252.

Biggar W D, Sturgess J M 1976 Peroxidase activity of alveolar macrophages. Laboratory Investigation 34: 31-42.

Brummer E, Morrison C J, Stevens D A 1985 Recombinant and natural gamma-interferon activation of macrophages in vitro: different dose requirements for induction of killing activity against phagocytizable and non-phagocytizable fungi. Infection and Immunity 49: 724-730.

Brummer E, Stevens D A 1984 Activation of murine polymorphonuclear neutrophils for fungicidal activity with supernatants from antigen-stimulated immune spleen cell cultures. Infection and Immunity 45: 447-452.

Brummer E, Sugar A M, Stevens D A 1983 Activation of it has been reported that recombinant $\gamma$-IFN induces a MPO-independent mechanism in macrophages that inhibits intracellular replication of Chlamydia psittaci (Rothermel et al., 1986).

Using viable organisms as stimuli for macrophages, we did not find enhanced superoxide anion production by activated macrophages in comparison with non-activated macrophages, when assessed by lucigenin CL. Killed $C$. albicans produced a 10-fold greater $\mathrm{CL}$ response than viable $C$. albicans and similar enhanced responses were induced by activated and non-activated macrophages. Others have used particulate material (opsonised zymosan) or soluble compounds such as phorbol myristate acetate as stimulants to demonstrate enhanced capacity of activated macrophages to generate superoxide anion or $\mathrm{H}_{2} \mathrm{O}_{2}$ (Murray et al., 1985). Although these stimuli distinguish activated from non-activated macrophages, extrapolation from enhanced superoxide anion and $\mathrm{H}_{2} \mathrm{O}_{2}$ production to their role as a microbicidal mechanism may be unwise as evidenced by our results with $C$. albicans presented here.

Candidacidal mechanisms of peritoneal macrophages activated in vitro by Con A supernates reported here resemble those recently described for human monocytes by Sasada et al. (1987). Killing of C. albicans $(35 \mathrm{SD} 5 \%$ ) by monocytes was inhibited by SOD, catalase or thiourea and was associated with MPO-positive cells. Monocytes cultured in vitro for 14 days differentiated into macrophages, became MPO negative, and failed to kill C. albicans. In this respect monocyte-derived macrophages were similar to resident murine peritoneal macrophages.

We acknowledge the presentation of this work to the Annual Meeting of the American Society for Microbiology 1987.

peritoneal macrophages by concanavolin A or Mycobacterium bovis $\mathrm{BCG}$ for fungicidal activity against Blastomyces dermatitidis and effect of specific antibody and complement. Infection and Immunity 39: 817-822.

Celada A, Gray P W, Rinderknecht E, Schreiber R D 1984 Evidence for a gamma-interferon receptor that regulates macrophage tumoricidal activity. Journal of Experimental Medicine 160: 55-74.

Chapes S K, Haskill S 1983 Evidence for granulocyte-mediated macrophage activation after $C$. parvum immunization. Cellular Immunology $75:$ 367-377.

Dahlgren C, Stendahl O 1983 Role of myeloperoxidase in luminol-dependent chemiluminescence of polymorphonuclear leukocytes. Infection and Immunity 39: 736-741.

DeChatelet L R et al. 1982 Mechanisms of luminol-dependent chemiluminescence of human neutrophils. Journal of Immunology 129 : 1589-1593.

Havell E A, Spitalny G L 1984 The glycoprotein nature of 
murine gamma interferon. Archives of Virology 80: 195207.

Heifets L, Imai K, Goren M B 1980 Expression of peroxidasedependent iodination by macrophages ingesting neutrophil debris. Journal of the Reticuloendothelial Society 28: 391404.

Kagaya K, Fukazawa Y 1981 Murine defense mechanism against Candida albicans infection. II. Opsonization, phagocytosis and intracellular killing of C. albicans. Microbiology and Immunology 25: 807-818.

Klebanoff S J 1968 Myeloperoxidase-halide-hydrogen peroxide antibacterial system. Journal of Bacteriology 95 : 2131-2138.

Lehrer R I 1972 Functional aspects of a second mechanism of candidacidal activity by human neutrophils. Journal of Clinical Investigation 51 : 2566-2572.

Lehrer R I, Cline M J 1969 Leukocyte myeloperoxidase deficiency and disseminated candidiasis: the role of myeloperoxidase in resistance to candida infection. Journal of Clinical Investigation 48: 1478-1488.

Lehrer R I, Ferrari L G, Patterson-Delafield J, Sorrell T 1980 Fungicidal activity of rabbit alveolar and peritoneal macrophages against Candida albicans. Infection and Immunity 28: 1001-1008.

Lehrer R I, Ladra K M, Hake R B 1975 Nonoxidative fungicidal mechanisms of mammalian granulocytes: demonstration of components with candidacidal activity in human, rabbit and guinea pig leukocytes. Infection and Immunity 11 : 12261234.

Leijh P C J, van den Barselaar M T, van Furth R 1977 Kinetics of phagocytosis and intracellular killing of Candida albicans by human granulocytes and monocytes. Infection and Immunity 17: 313-318.

Minkenberg I, Ferber E 1984 Lucigenin-dependent chemiluminescence as a new assay for NADP(H)-oxidase activity in particulate fractions of human polymorphonuclear leukocytes. Journal of Immunological Methods 71 : 61-67.

Muller-Peddinghaus R 1984 In vitro determinations of phagocyte activity by luminol- and lucigenin-amplified chemiluminescence. International Journal of Immunopharmacology 6: $455-466$.
Murray H W, Rubin B Y, Rothermel C D 1983 Killing of intracellular Leishmania donovani by lymphokine-stimulated human mononuclear phagocytes. Evidence for interferongamma as the activating lymphokine. Journal of Clinical Investigation 72: 1506-1510.

Murray H W, Rubin B Y, Carriero S M, Harris A M, Jaffee E A 1985 Human mononuclear phagocyte antiprotozoal mechanisms: oxygen-dependent vs. oxygen independent activity against intracellular Toxoplasma gondii. Journal of Immunology 134: 1982-1988.

Patterson-Delafield J, Martinez R J, Lehrer R I 1980 Microbicidal cationic proteins in rabbit alveolar macrophages: a potential host-defense mechanism. Infection and Immunity 30: $180-192$.

Peterson P K, Gaziano E, Suh H J, Devalon M, Peterson L, Keane W F 1985 Antimicrobial activities of dialysateelicited and resident human peritoneal macrophages. Infection and Immunity 49: 212-218.

Rothermel C D, Rubin B Y, Jaffee E A, Murray H W 1986 Oxygen-independent inhibition of intracellular Chlamydia psittaci growth by human monocytes and interferon- $\gamma$ activated macrophages. Journal of Immunology 137: 689692.

Sasada M, Johnston R B 1980 Macrophage microbicidal activity. Correlation between phagocytosis-associated oxidative metabolism and the killing of Candida by macrophages. Journal of Experimental Medicine 152: 85-98.

Sasada et al. 1987 Candidacidal activity of monocyte-derived human macrophages: relationship between candida killing and oxygen radical generation by human macrophages. Journal of Leukocyte Biology 41 : 289-294.

Sugar A M, Chahal R S, Brummer E, Stevens D A 1983 Susceptibility of Blastomyces dermatitidis strains to products of oxidative metabolism. Infection and Immunity 41: 908912.

Svedersky L P, Benton C V, Berger W H, Rinderknecht E, Harkins R N, Palladino M A 1984 Biological and antigenic similarities of murine interferon- $\gamma$ and macrophage-activating factor. Journal of Experimental Medicine 159: 812-827. 